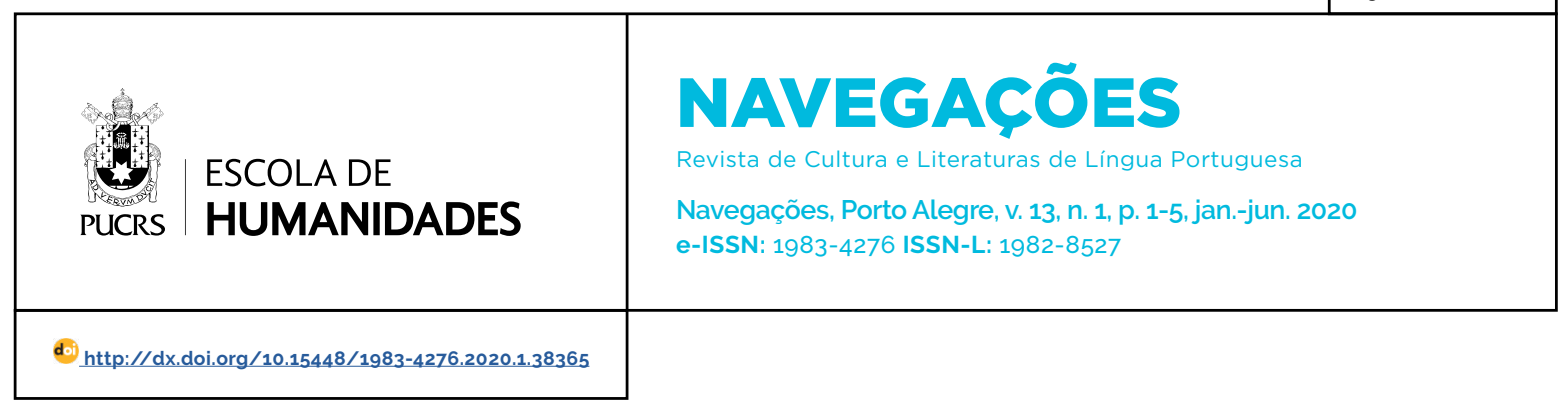

SEÇÃO: ENTREVISTAS

\title{
Entrevista com Ana Mafalda Leite: o Oriente é um bordado oculto na história de Moçambique
}

An interview with Ana Mafalda Leite: The Orient is a hidden embroidery in the history of Mozambique

\section{Gustavo Henrique \\ Rückert ${ }^{1}$ \\ orcid.org/0000-0002-9267-5229 \\ gh.ruckert@gmail.com}

Recebido em: 04 jun. 2020 Aprovado em: 04 jun. 2020. Publicado em: 10 ago. 2020.
Ana Mafalda Leite nasceu em Portugal e passou sua infância em Moçambique. Atualmente, é professora de Literaturas Africanas na Universidade de Lisboa. Seus numerosos e prestigiados escritos, que transitam entre artigos, ensaios, resenhas e poemas, destacam-se pelo tensionamento das ideias de identidade, pertencimento e fronteira.

É autora dos livros teórico-criticos A poética de José Craveirinha (1991), Modalização épica nas Literaturas Africanas (1995), Oralidades \& escritas nas Literaturas Africanas de Lingua Portuguesa (1998), Literaturas africanas e formulações pós-coloniais (2003), Oralidade \& escritas pós-coloniais (2012), Cenografias pós-coloniais (2013), Cenografias pós-coloniais \& estudos sobre Literatura Moçambicana (2018), Ensaios teóricos \& estudos sobre Literatura Moçambicana (2019). Como poeta, publicou Em sombra acesa (1984), Canções de Alba (1989), Mariscando luas (com Luis Carlos Patraquim e Roberto Chichorro, 1992), Rosas da China (1999), Passaporte do coração (2002), Livro das encantações (2005), Livro das Encantações e Outros Poemas (Antologia, 2010), O amor essa estranha forma de desconhecimento (2010), Outras fronteiras: fragmentos de narrativas (2017) e Outras Fronteiras (2019).

Pensadora fronteiriça (entre Portugal e Moçambique, a prosa e o verso, o ensaio e a poesia, a escrita e a oralidade, a modernidade e a tradição, a pesquisa e a experiência), Leite é uma das vozes mais qualificadas para contribuir com um pensamento critico a respeito das geografias culturais, sociais e politicas herdadas do mundo colonial e toda a carga de significação envolvendo os nomeados orientes. As perguntas que seguem foram gentilmente respondidas a mim por meio eletrônico, em maio de 2020. 
Ana Mafalda foi um importante navio do Século XX a fazer o trânsito entre Portugal e África. Em alguns dos teus poemas, a figura do navio é evocada como figuração do sujeito-lírico. Poderiamos pensar Ana Mafalda como uma poeta transoceânica? E a ensaísta, também teria esse aspecto de deslocamento?

"Tenho o nome de um barco" é um poema incluido em Livro das Encantações (2005) e nasce de uma pergunta que fiz a minha mãe (devo-lhe o poema) sobre a razão do meu nome, Ana Mafalda, que sempre apreciei (pleno da vogal $a$, do ritmo ondulante do $n$ e do $m$ e a vela do $l$ ), ao que ela me respondeu, tens um nome de um barco. Após alguma pesquisa, descobri que assim era. Um barco que fazia ligação entre Portugal e as então colónias. Achei a escolha espantosamente adequada ao meu percurso pessoal e dai ter escrito aquele poema de cariz autobiográfico e de reflexão de partilhas identitárias e de pertenças: "ana mafalda um barco do império em travessia entre dois/ oceanos me fez nascer. foi esse o nome que me deram ao/ levar-me transplantada de um hemisfério para o outro./ nasci entre fronteiras líquidas entre ondas inventei um/ berço. foi um nome que me nasceu, foi um barco, um/ deslizar de marés no final da década de cinquenta [...]".

Com efeito, a minha poesia tem barcos, ilhas, viagens, uma relação intensa com o índico e, por exemplo, no livro Passaporte do Coração (2002), que se centra na ltha de Moçambique, procuro desvelar uma memória histórica e cultural do norte de Moçambique, que se adequa aos meus trânsitos pessoais e aos trânsitos da história literária do país. É aí que nasce o primeiro poeta, Campos de Oliveira, e estão presentes signos das culturas costeiras do Índico.

Com efeito até ao final do século XIX (1898), a capital de Moçambique era na Ilha e há uma longa história de contactos comerciais com o islão, o universo suaíli e a Índia, que acabam por ser quase esquecidos com a mudança da capital para o sul e a prevalência deste na época colonial mais recente e na luta pela independência. Ao escrever Passaporte do Coração, motivou-me a vi- sitação demorada de um imaginário da literatura, presente na história e na cultura moçambicanas.

Escrevi na introdução do livro: "Caminho entre dois paises e duas literaturas, viajo criativamente entre eles, também nessa partilha de que o império tem memória: transplantada para Moçambique com meses de idade, aí cresci até aos 19 anos. Não posso recusar-me passado e presente, terra, culturas, mar e céu. Sou dessa ambivalência ao nascer-me nela, a criação de um lugar de travessia e de tapeçaria cultural. Roubo a Salman Rushdie um título que julgo adequado a esta minha partilha de e entre mundos: Imaginary homelands - terras-mãe, pátrias, imaginárias. [...] Ilha, sinédoque também, ainda que parcelar e filigrânica, do país que é Moçambique, de uma vivência que partilho e revivo, afeiçoada com uma presença variada da Índia no quotidiano, ou com a longínqua litania das rezas corânicas, a mansa quietude do índico, o ritmo langoroso, habitual, da mistura de muitas linguas e rostos de cores diferentes".

No fundo há sempre uma articulação indirecta e simultaneamente intencional entre a minha investigação na área da literatura moçambicana e na área da criação poética. Estudar a literatura moçambicana, no quadro das literaturas africanas, foi também uma forma de pensar e articular as minhas origens. Tendo vindo para Portugal finalizar os meus estudos universitários, foram as formas afectivas de conhecimento e de desvendamento do país recém-independente que encontrei na poesia e no ensaio, para nunca deixar Moçambique, e de nele me encontrar, tatuada pela escrita do ensaio e da criação.

Como é lidar com esses dois lugares distintos de escrita: a poesia e o ensaio? Há relação entre ambos? O prestígio como pesquisadora da UL auxilia ou atrapalha a recepção da obra poética? E o reconhecimento como poeta auxilia ou atrapalha a carreira acadêmica?

Até uma certa fase da minha carreira universitária articulei de forma mais ou menos paritária a escrita poética e a ensaística. Mas, por razões de trabalho, tive de dar sempre mais atenção ao 
percurso universitário, o que levou a não poder projectar mais a publicação poética e a dar-lhe a devida divulgação. Reconheço que desperdicei algumas oportunidades e não soube por vezes articular adequadamente as duas facetas.

Tentei também fazer a edição em Portugal e Moçambique, porque queria que a minha poesia fosse lida nos dois países. Depois de estar sem editar poesia em Portugal desde 2005 (Livro das Encantações), vou este ano editar em Portugal (já o fiz em Moçambique em 2010), uma antologia de poesia (1984-2019) intitulada Janela para o índico, como forma de dar a conhecer os meus últimos livros. Nela incluo uma obra publicada primeiramente no Brasil (2017), e depois de um pouco modificada, em Moçambique (2019), Outras Fronteiras Fragmentos de Narrativas.

Além disso, estou actualmente a criar um site pessoal onde procuro fazer paulatinamente a descrição de um trajecto pessoal de diferentes escritas: https://cesa.rc.iseg.ulisboa.pt/anamafaldaleite.

\section{O que Ana Mafalda entende por Oriente?} Qual sua relação com ele?

Para falar de Oriente remeto para as delimitações que Said faz no seu estudo Orientalismo (1990). Por um lado o Extremo Oriente (India, Japão, China e outras regiões) e o Oriente Próximo, ou do Islão e dos árabes, considerando em especial a produção de conhecimento inglesa, francesa e americana, sobre os árabes e o Islão, que, segundo o autor, representaram o Oriente durante quase mil anos.

É seguindo este conjunto de sinais que eu tentei observar como é representado o Oriente da Itha de Moçambique na obra de Rui Knopfli ("A Construção do Oriente em A llha de Próspero de Rui Knopfli", Leite, 2018), perceber o que a palavra significa e para o que remete, na sua tessitura intertextual e cultural. Conclui que a noção de "Oriente" a que se refere o poeta nos textos, engloba apenas uma parte do Extremo Oriente (Índia) e alicerça-se deste modo nos textos sagrados do hinduísmo, parcialmente citados e referidos.

Mas, há um outro Oriente, que não é designado como tal, nos poemas de Rui Knopfli, o Próximo Oriente, a que se refere Said, do Islão e dos árabes, representado também nos poemas de $A$ llha de Próspero, muitas vezes a par do anterior, mas sem nunca ser expressamente referido enquanto tal. Com efeito este Oriente islâmico co-existe no Extremo Oriente, uma vez que a presença do Islão é também muito importante naquelas regiões, nomeadamente no Paquistão.

A Itha de Moçambique é representada em $A$ Ilha de Próspero de Rui Knopfli enquanto espaço de outros imaginários e formações discursivas, alheias a Próspero, e é uma das primeiras obras da literatura moçambicana que abre o seu espaço de reflexão para o Índico através da representação do(s) Oriente(s) que dele fazem parte, enquanto partilha de um contexto regional, ou transnacional mais amplo. O livro de Rui Knopfli, entre outros temas desenvolvidos, encena o Oceano Índico a partir da representação diversa do Oriente na llha de Moçambique, questionando Próspero e o poder colonial.

Concluindo, para mim, o Oriente é um bordado oculto na história de Moçambique, como no conto de João Paulo Borges Coelho O Pano Encantado, esquecido pela prevalência do Sul na recente história da luta anti-colonial, protagonizada por essa região do país.

Tua pesquisa mais recente, Narrativas do Oceano Índico no Espaço Lusófono, revela o espaço do Oceano Índico como potencialmente diversificado, no qual confluem diferentes culturas. Na tua poesia, este oceano também surge como locus privilegiado, zona de contato entre as mais diferentes vozes e responsável por um olhar de deslocamento. Qual a importância do Índico para ti? Que orientes se pode vislumbrar a partir da costa moçambicana?

Trata-se, por um lado, de evocar a pertença do país a uma história muito antiga (e socorro-me aqui da historiadora Joana Pereira Leite), legado inexorável da geografia, que remonta aos laços que o Corredor Swahili estabeleceu, tal como consagrado pela recente arqueologia histórica, quer com o sistema mundo do oriente, até ao 
século IX DC, quer posteriormente com o Mediterrâneo, através do Mar Vermelho, a partir do século X. Sabe-se hoje que, da costa leste africana setentrional (Somália atual) às margens indicas meridionais, litoral da África Austral (Moçambique actual), as comunidades africanas na sua origem, estabelecidas desde o início do primeiro milénio, e sustentadas numa vida material ligada ao mar, abrem-se ao mundo por via do comércio transoceânico (madeira, escravos, ambergris, ouro, marfim, quartzo) e associam às identidades de origem elementos da cultura material, política e religiosa arabo-islâmica.

Numa história mais recente, no final do século XVIII, a Ilha de Moçambique era uma placa giratória do comércio no Oceano Índico Ocidental. Com a atividade de Mombaça, Quiloa, Zanzibar, Ibo e Quelimane, ela era parte integrante de um dispositivo de trocas comerciais. As sociedades costeiras e insulares - sociedades intermediárias entre o mar e o continente propriamente dito do Norte de /Moçambique têm uma espécie de dupla pertença por desenvolverem relações especificas com as sociedades continentais de Moçambique e com outras do Oceano Índico. São sociedades que funcionam na base de uma economia maritima, marinheiros, pescadores, fabricantes de barcos, mercadores. Estiveram, historicamente, em contacto com os diferentes pólos de comércio do Oceano Índico.

Nesse sentido o islão no Norte de Moçambique constitui-se fundamentalmente como uma forma ideológica estruturante das relações mercantis e age como elemento unificador para as trocas a longa distância entre a costa africana, a Índia e - Sul da Arábia. A chegada dos portugueses e da religião cristã vai tentar destruir esta antiga base costeira de dominação suaíli, árabe e indiana.

Em alguns ensaios, tu destacas uma certa ideia de Oriente presente em importantes nomes da Literatura Moçambicana, como Virgílio de Lemos, Glória de Sant'Anna, Rui Knopfli, Luís Carlos Patraquim, Eduardo White, Mia Couto ou João Paulo Borges Coelho. Qual importância o Oriente tem para a Literatura de Moçambique?
Rui Knopfli e Virgílio de Lemos pertencem à primeira geração de autores que escrevem sobre a Ilha de Moçambique, situada no extremo norte do país, e o seu projecto de escrita situa-se ainda em contexto colonial, diferentemente do que vem a acontecer, mais tarde, com outros autores, que no pós-independência vão celebrar aquele lugar de distintas maneiras. É um espaço cultural, por excelência, uma vez que nele nasceu a primeira voz poética do século XIX, Campos de Oliveira, e se tornou lugar de referência para o conceito de "nação cultural", reinventando outras origens que não as do gesto épico fundador do sul. Por outro lado a insistência no mar de Pemba, o Índico, velado na poesia de Glória de Sant'Anna, evoca a sua importância, também no quadro da época colonial.

Talvez porque a minha vivência tenha sido no norte de Moçambique, onde cresci, quando cheguei ao sul, senti as diferenças. E, posteriormente, nos estudos sobre poesia, relação entre a oralidade e a escrita, culturas do sul e do norte. percebi que havia um mosaico cultural diferenciado e muito rico no país.

O norte com ligações a um oriente "difuso" ou a "orientes" diversos, que a palavra índico melhor conjuga, uma vez que é nesse oceano que se fazem os contatos mercantis, simultaneamente culturais, com diversas regiões do oriente. Eu usaria a palavra Índico em vez de Oriente.

Dando sequência à questão anterior, na cena literária contemporânea de Moçambique, quais imagens do Oriente, ou do Índico, têm surgido?

Julgo que mais do que imagens do Oriente, são as imagens do Norte e do Índico que têm ganho um lugar importante nas diferentes paisagens da prosa e da poesia. Os escritores têm reescrito o norte de Moçambique, veja-se Choriro, de Ungulani Ba Ka Khosa, ou as narrativas de Mia Couto, algumas que se centram na Beira, integrando personagens de origem indiana e chinesa. Gostaria de evidenciar um importante romance como O Outro Pé da Sereia, onde é reinventada a memória da viagem da Índia para Moçambique.

Também a reescrita da relação com as culturas 
costeiras do Índico é tratada muito especialmente por João Paulo Borges Coelho nas suas obras Indicos Indícios, As Visitas do Dr. Valdez. O autor, que tem ascendentes familiares no lbo, tal como o poeta Júlio Carrilho, e uma vivência pessoal que percorre universos como Tete e a Beira, deslocou a ficção moçambicana para o centro e norte do pais em romances relevantes como As Rainhas da Noite ou Ponta Gea.

Ainda sobre este norte índico e insular escreveram Júlio Carrilho, Eduardo White, Adelino Timóteo, Sangare Okapi, Chagas Levene, mais recentemente Leo Cote. Poetas mais jovens do norte, como Lino Mukurruza, destacam-se pela deslocalização cultural no país, nomeadamente este último criou um clube de leitura em Angoche e tem um site no facebook em que divulga a prática de leitura de livros. Por exemplo, o meu Passaporte do Coração já aí foi objeto de leitura.

Edward Said, no seu clássico Orientalismo: o oriente como invenção do ocidente, destaca uma tradição discursiva ocidental responsável pela configuração e manutenção de uma imagem colonial sobre o Oriente. $O$ discurso orientalista utilizou-se, sobretudo, da literatura entre os séculos XV e XIX para sua propagação. Em Língua Portuguesa, importantes nomes, como Camões, Côrte-Real, Mendes Pinto, Eça ou Pessoa, entre tantos outros, construíram e/ ou veicularam uma série de estereótipos sobre - Oriente. Qual o papel do escritor de Língua Portuguesa, hoje, em relação a essa tradição orientalista? A Literatura teria potencial para descolonizar os múltiplos orientes?

O orientalismo, tal como Said o estuda, baseia-se na exterioridade, isto é, no facto de o orientalista, poeta ou erudito, fazer falar o Oriente, descrever o Oriente, e verificamos que o principal resultado desta exterioridade se concretiza, claro está, na representação. Qualquer pessoa que escreva sobre o Oriente, ainda na esteira do pensamento de Said, deve ter uma perspectiva sobre ele, e no texto, esta posição inclui, entre outros aspectos, o tipo de voz narrativa que se adopta, o tipo de estrutura que se constrói, os tipos de imagens utilizados, os temas e os motivos que circulam no texto, a que devemos acrescentar os modos deliberados de interpelação ou relação com o leitor, enfim todos os procedimentos de representar o Oriente, ou de falar em seu nome. Neste a representação serve-se de uma variedade de elementos, que incluem a enunciação e as práticas retórico-narratológicas.

Julgo que actualmente os escritores, principalmente através da memória, ou da pós-memória, estão conscientes dessa reinvenção desconstrutiva necessária, que tem tido lugar em vários romances de língua portuguesa que versam sobre a descolonização e o império. Apenas a título de exemplo, cito Viagem para a Índia de Gonçalo M. Tavares, Um Estranho em Goa de José Eduardo Agualusa, O Outro Pé da Sereia de Mia Couto, Era uma vez em Goa de Paulo Varela Gomes, Requiem para um Navegador Solitário de Luis Cardoso. Julgo que as representações de Moçambique, Goa e Timor nas literaturas em lingua portuguesa contemporâneas constituem um arquivo crítico de memória histórica e colonial e das configurações do "oriente".

\section{Gustavo Henrique Rückert}

Doutor em Literaturas Portuguesa e Luso-Africanas pela Universidade Federal do Rio Grande do Sul (UFRGS). Professor de Literaturas em Lingua Portuguesa na Universidade Federal dos Vales do Jequitinhonha e Mucuri (UFVJM).

\section{Endereço de correspondência}

Faculdade Interdisciplinar em Humanidades / UFVJM. Campus JK, Rodovia MGT 367 - Km 583, n 5000

Alto da Jacuba, Diamantina - MG,

CEP 39100-000. 